\title{
A New Experimental Model of ARDS and Pulmonary Hypertension in the Dog*
}

\author{
B.Zwissler ${ }^{1}$, H.Forst ${ }^{2}$, K. Ishii ${ }^{3}$, and K.Messmer ${ }^{1}$ \\ ${ }^{1}$ Department of Experimental Surgery, University of Heidelberg, Heidelberg, \\ Federal Republic of Germany \\ ${ }^{2}$ Department of Anesthesiology, University of Munich, Medical Center Großhadern, \\ Munich, Federal Republic of Germany \\ ${ }^{3}$ 2nd Department of Surgery, Miyazuki Medical College, Kihara Kiyotake-cho, Japan
}

\begin{abstract}
Summary. The aim of this study was to establish a stable and reproducible model of pulmonary artery hypertension with concomitant ARDS-like changes of lung function and lung morphology. In eight anesthetized and ventilated dogs, $0.01 \mathrm{ml} / \mathrm{kg}$ oleic acid $(\mathrm{OA})$ was given i.v. followed by repetitive injections of $100 \mu \mathrm{m}$ glass beads (GB) into the right atrium until a mean pulmonary artery pressure of $35-40 \mathrm{~mm} \mathrm{Hg}$ was reached. Mean right ventricular (RVP) and pulmonary artery (PAP) pressures, pulmonary vascular resistance (PVR), lung compliance and resistance, $\mathrm{PaO}_{2}$, intrapulmonary shunt and colloidosmotic pressure (COP) were closely monitored for $150 \mathrm{~min}$. PAP, RVP, and PVR considerably increased subsequent to OA/ GB injection, and stabilized at a high level within $70 \mathrm{~min}$, showing only a minimal decrease (PAP, RVP) or no change (PVR) during the following $80 \mathrm{~min}$. A significant decrease of $\mathrm{PaO}_{2}$ and pulmonary compliance as well as an increase of resistance and intrapulmonary shunt were found as early as $30 \mathrm{~min}$ after the last embolization and they remained unchanged for $120 \mathrm{~min}$. Reduction of COP suggested transcapillary leakage of macromolecules. Histology revealed an interstitial and intraalveolar edema. We conclude that the combined injection of oleic acid and glass beads provokes microvascular lung injury and results in stable pulmonary artery hypertension with concomitant ARDS-like changes of lung function. Thus, an acute model is provided in the dog allowing for the study of cardiac function in ARDS complicated by pulmonary artery hypertension.
\end{abstract}

Key words: Adult respiratory distress syndrome - Pulmonary artery hypertension, Model of - Hemodynamics - Lung function

\footnotetext{
*Supported by Deutsche Forschungsgemeinschaft grant SFB 320/C3. Parts of this work were presented at the European Society for Surgical Research XXIII Congress/Joint meeting with the European Shock Society, Bologna, Italy, 2-5 May, 1988

Offprint requests to: Dr. Bernhard Zwissler
} 


\section{Introduction}

The onset of pulmonary artery hypertension $(\mathrm{PAH})$ in patients suffering from adult respiratory distress syndrome (ARDS) has been shown to further increase the mortality rate of this syndrome [33]. Several authors have proposed that when ARDS is complicated by elevation of pulmonary vascular resistance (PVR), ventricular contractility is compromised and the patients' prognosis deteriorates [36].

To study cardiac function in the presence of both PAH and ARDS, a suitable experimental model is needed in which elevated PVR and the characteristic symptoms of ARDS (microvascular lung injury/pulmonary edema, impairment of lung mechanics/gas exchange) are present simultaneously. Both ARDS and $\mathrm{PAH}$ should be stable and easy to induce within a short period of time.

Different models have been developed in the past. Most of them, however, mimic only single aspects of ARDS or PAH. The techniques used include pulmonary microembolization (e.g., glass beads [5, 22, 26, 28], fat emboli [4], oleic acid [3, 12, 19, 40], starch granules [9], alpha-naphthyl-thiourea (ANTU) [21], blood clots [39], air [40], barium sulfate [25]) and the intravenous (thrombin [1, 27], bacteria [8,38], endotoxin [7, 15], lycopodium spores [13], heroin, alloxan, pyrroles [21]), intratracheal (ozone [34], $\mathrm{HCl}$ [16], papain [30]) or intraperitoneal (ammonium sulfate [21]) administration of agents. Most often PAH was induced by constriction or occlusion of the pulmonary artery [10, 32].

However, none of these models meets all criteria of both the ARDS and PAH mentioned above. Therefore, we have combined two methods commonly used for induction of either PAH (glass beads; GB) or ARDS (oleic acid; OA). After administration of these the time-course of changes in hemodynamics and lung function and alterations of lung morphology were examined.

By developing and characterizing an acute animal model, we tried to encompass the clinical features of both ARDS and PAH as closely as possible in order to allow for evaluation of cardiac function under these conditions.

\section{Material and Methods}

The study has been performed in eight foxhounds $(22 \pm 4 \mathrm{~kg})$ of either sex. After premedication with $2-3 \mathrm{ml}$ propiomazine (Combelen, Bayer, Leverkusen, FRG), anesthesia was induced by $20 \mathrm{mg} / \mathrm{kg}$ pentobarbital i.v. (Nembutal, Ceva, Bad Segeberg, FRG) and maintained by infusion of $5 \mathrm{mg} \mathrm{kg}^{-1} \mathrm{~h}^{-1}$ pentobarbital, $150 \mu \mathrm{g} \mathrm{kg}^{-1} \mathrm{~h}^{-1}$ piritramid (Dipidolor, Janssen, Neuss, FRG) and $75 \mu \mathrm{g} \mathrm{kg}^{-1} \mathrm{~h}^{-1}$ alcuronium (Alloferin, Roche, Grenzach-Wyhlen, FRG). Ringer's solution $5 \mathrm{ml} \mathrm{kg}^{-1} \mathrm{~h}^{-1}$ was administered throughout the experiment. The dogs were intubated and mechanically ventilated with a respiratory rate (RR) of $12 \mathrm{cycles} / \mathrm{min}$ at a tida volume $\left(\mathrm{V}_{\mathrm{T}}\right)$ of $18 \mathrm{ml} / \mathrm{kg}$ using $100 \% \mathrm{O}_{2}$ (Servo $900 \mathrm{C}$, Siemens-Elema, Solna, Sweden).

\section{Surgical Preparation}

Fluid-filled catheters (PP270, Portex, Hythe, UK) were positioned in the aorta and the vena cava superior. A Swan-Ganz catheter (7F, Edwards, Anasco, Puerto Rico) was inserted into the pulmonary artery. For determination of ventricular pressures, precalibrated micromanometers (PC-350, Millar Instruments, Houston, Tex., USA) were introduced into the left ventricle (LV) via the right carotid artery and into the right ventricle (RV) via the right atrium. 


\section{Measurements}

Measurements were performed with the dogs in the left lateral position. Mean arterial (MAP), central venous (CVP) and pulmonary artery (PAP) pressures were recorded using Statham P23D6 transducers (Gould-Statham, Oxnard, Calif., USA) referred to the right atrium and zeroed to atmospheric pressure. Cardiac output $(\mathrm{CO})$ was measured in triplicate using thermodilution technique (SP 1435, Gould-Statham). Arterial and mixed venous blood was analyzed for $\mathrm{PO}_{2}, \mathrm{PCO}_{2}$, and $\mathrm{pH}$. $\mathrm{CO}_{2}$ production per minute $\left(\dot{\mathrm{VCO}}_{2}\right)$ was measured by a $\mathrm{CO}_{2}$-Analyzer 930 (Siemens-Elema, Solna, Sweden). Effective pulmonary compliance $\left(\mathrm{C}_{\mathrm{eff}}\right)$ and expiratory resistance $\left(R_{\text {exp }}\right)$ were assessed by a Lung Mechanics Calculator 940 (SiemensElema, Solna, Sweden) connected to the respirator. Colloidosmotic pressure (COP) was determined by an Osmomat 050 (Gonotec, Berlin, FRG).

\section{Experimental Protocol}

After surgical preparation, the animals were isovolemically hemodiluted with dextran 60 (Makrodex 6\%, Schiwa, Glandorf, FRG) to a hematocrit (Hct) of $30 \%$ and were allowed to stabilize for $30 \mathrm{~min}$. Hematocrit has been intentionally decreased, because most patients with ARDS - consequent on their systemic illness or because of multiple blood sampling - are also anemic. The blood removed was used for the replacement of volume losses resulting from laboratory analyses. Hemodilution per se has been shown to affect neither extravascular lung water nor gas exchange during $\mathrm{OA}$-induced pulmonary edema in dogs [6]. Following a control measurement, $0.01 \mathrm{ml} / \mathrm{kg} \mathrm{OA}$ (Merck, Darmstadt, FRG) was injected into the right atrium during expiration. Thereafter, non-siliconized $100 \mu \mathrm{m}$ glass beads (LDH, Heidelberg, FRG) were suspended in dextran 60 , thoroughly mixed and injected into the right atrium in aliquots of $0.5-1 \mathrm{~g}$ every $3-5 \mathrm{~min}$ until PAP had reached $35-40 \mathrm{~mm} \mathrm{Hg}$. Between 10 and $150 \mathrm{~min}$ after the last injection of $\mathrm{GB}\left(\mathrm{T}_{10}-\mathrm{T}_{150}\right)$, central hemodynamics and lung function were assessed every 20 and $40 \mathrm{~min}$, respectively. At $\mathrm{T}_{150}$, the animals were killed with $\mathrm{KCl}$; the lungs and the heart were removed and sent for histological examination.

\section{Calculations}

The following hemodynamic parameters were calculated: $\mathrm{SV}=\mathrm{CO} \cdot 1000 / \mathrm{HR}, \mathrm{CI}=10 \cdot \mathrm{CO} /$ $\mathrm{BW}^{(0.75)}$ (according to $\left.[20]\right), \mathrm{SI}=\mathrm{CI} \cdot 1000 / \mathrm{HR}, \mathrm{PVR}=(\mathrm{PAP}-\mathrm{LVEDP}) \cdot 79.9 / \mathrm{CO}, \mathrm{SVR}=$ $(\mathrm{MAP}-\mathrm{RVEDP}) \cdot 79.9 / \mathrm{CO}, \mathrm{RVSW}=\mathrm{PAP} \cdot \mathrm{CO} \cdot 0.133 / \mathrm{HR}$ and $\mathrm{LVSW}=\mathrm{MAP} \cdot \mathrm{CO} \cdot 0.133 /$ $\mathrm{HR}$, where $\mathrm{SV}=$ stroke volume, $\mathrm{HR}=$ heart rate, $\mathrm{CI}=$ cardiac index, $\mathrm{BW}=$ body weight, $\mathrm{SI}=$ stroke index, $\mathrm{PVR}=$ pulmonary vascular resistance, $\mathrm{LVEDP}=\mathrm{LV}$ end-diastolic pressure, $\mathrm{SVR}=$ systemic vascular resistance, $\mathrm{MAP}=$ mean aortic pressure, $\mathrm{RVSW}=\mathrm{RV}$ stroke work, $\mathrm{RVEDP}=\mathrm{RV}$ end-diastolic pressure, and LVSW $=\mathrm{LV}$ stroke work.

Intrapulmonary shunt $\left(\dot{Q}_{\mathrm{s}} / \dot{\mathrm{Q}}_{\mathrm{t}}\right)$ was calculated as $\dot{\mathrm{Q}}_{\mathrm{s}} / \dot{\mathrm{Q}}_{\mathrm{t}}=\left(\mathrm{C}_{\mathrm{c}} \mathrm{O}_{2}-\mathrm{C}_{\mathrm{a}} \mathrm{O}_{2}\right) /\left(\mathrm{C}_{\mathrm{c}} \mathrm{O}_{2}-\mathrm{C}_{\overline{\mathrm{V}}} \mathrm{O}_{2}\right)$, where $\mathrm{C}_{\mathrm{c}} \mathrm{O}_{2}=\mathrm{Hb} \cdot 1.39+0.0031 \cdot\left(\mathrm{P}_{\mathrm{B}}-47-\mathrm{P}_{\mathrm{a}} \mathrm{CO}_{2}\right) \cdot \mathrm{C}_{\mathrm{c}} \mathrm{O}_{2}, \mathrm{C}_{\mathrm{a}} \mathrm{O}_{2}$ and $\mathrm{C}_{\overline{\mathrm{V}}} \mathrm{O}_{2}$ are $\mathrm{O}_{2}$ contents in ideal $(100 \%$ saturated) pulmonary capillary, systemic arterial and mixed venous blood, respectively. $\mathrm{P}_{\mathrm{B}}$ is barometric pressure, $\mathrm{P}_{\mathrm{a}} \mathrm{O}_{2}$ and $\mathrm{P}_{\mathrm{a}} \mathrm{CO}_{2}$ are arterial $\mathrm{PO}_{2}$ and $\mathrm{PCO}_{2}$, respectively. Physiological dead space/tidal volume ratio $\left(\mathrm{V}_{\mathrm{D}} / \mathrm{V}_{\mathrm{T}}\right)$ was determined by the Enghoff modification of the Bohr equation as $\mathrm{V}_{\mathrm{D}} / \mathrm{V}_{\mathrm{T}}=\left(\mathrm{P}_{\mathrm{a}} \mathrm{CO}_{2}-\mathrm{P}_{\mathrm{E}} \mathrm{CO}_{2}\right) \cdot 100 / \mathrm{P}_{\mathrm{a}} \mathrm{CO}_{2}$ [14], where $\mathrm{P}_{\overline{\mathrm{E}}} \mathrm{CO}_{2}$ (partial pressure of mean expiratory $\mathrm{CO}_{2}$ ) was calculated as $\mathrm{P}_{\overline{\mathrm{E}}} \mathrm{CO}_{2}=\dot{\mathrm{V}} \mathrm{CO}_{2} \cdot\left(\mathrm{P}_{\mathrm{B}}-47\right) /$ $\left(\mathrm{V}_{\mathrm{T}} \cdot \mathrm{RR}\right)$. The alveolar gas equation was used to calculate the alveolar-arterial $\mathrm{O}_{2}$ difference $\left(\mathrm{AaDO}_{2}\right)$.

\section{Statistical Analysis}

Data are presented as means $\pm \mathrm{SD}$. The existence of an overall effect of $\mathrm{OA} / \mathrm{GB}$ was tested by repeated measures analysis of variance (rANOVA). Only in the case of a significant rANOVA $(P<0.05)$ were further statistics performed. To estimate the significance of changes after $\mathrm{OA} / \mathrm{GB}$, data at $\mathrm{T}_{10}, \mathrm{~T}_{30}$, and $\mathrm{T}_{150}$ were compared with control values by a 
Table 1. Sequence of changes in hemodynamics, respiration, blood gases and blood chemistry (not shown in the figures) after OA/GB injection

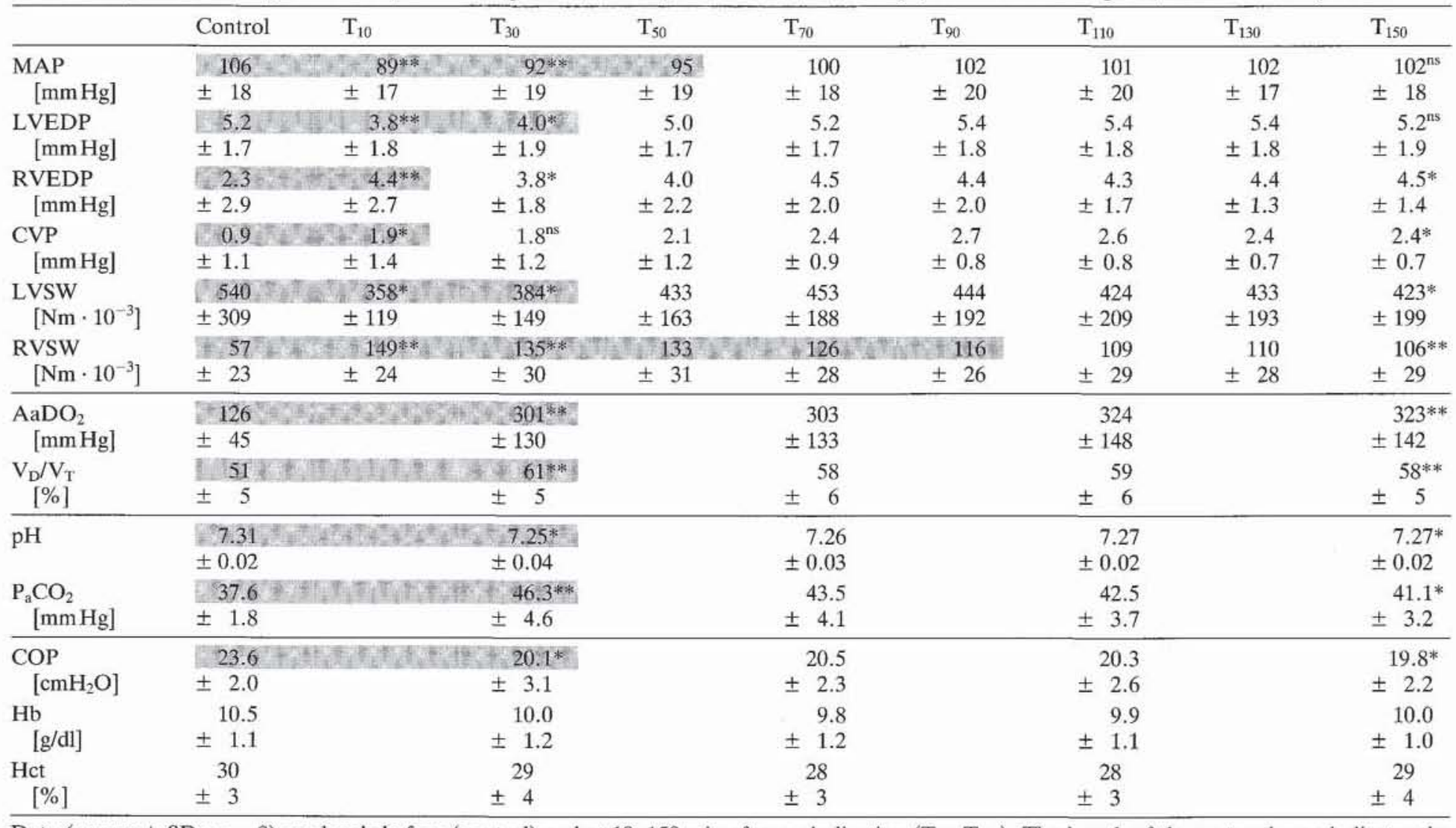

Data (means $\pm \mathrm{SD} ; n=8$ ) are levels before (control) and at 10-150 min after embolization $\left(\mathrm{T}_{10}-\mathrm{T}_{150}\right)$. The length of the rastered area indicates the time needed for each parameter to stabilize, while the rest of time up to $T_{150}$ and not marked by a raster indicates the plateau without any significant trend of the data to higher or lower values (for statistics see Methods). The estimate the significance of acute and long-term effects after OA/GB, data at $\mathrm{T}_{10}$ (hemodynamics), $\mathrm{T}_{30}$ and $\mathrm{T}_{150}$ have been compared with control data by means of Student's $t$-test $(* P<0.05 ; * * P<0.01)$

MAP, mean aortic pressure; LVEDP, left ventricular end-diastolic pressure; RVEDP, right ventricular end-diastolic pressure; CVP, central venous pressure; LVSW, left ventricular stroke work; RVSW, right ventricular stroke work; $\mathrm{AaDO}_{2}$, alveolar-arterial $\mathrm{O}_{2}$ difference; $\mathrm{V}_{\mathrm{D}} / \mathrm{V}_{\mathrm{T}}$, physiological dead space; $\mathrm{P}_{\mathrm{a}} \mathrm{CO}_{2}$, partial pressure of arterial $\mathrm{CO}_{2} ; \mathrm{COP}$, colloidosmotic pressure; $\mathrm{Hb}$, hemoglobin; Hct, hematocrit 
paired $t$-test (significance taken as $P<0.05$ ). To determine the timepoint at which OA/GB ceased to have directed effects on the parameters, Helmert analysis was performed (SAS, GLM/Helmert). Starting from $T_{10}$, this technique compares the mean value of each measurement with the mean of all subsequent measurements. According to this analysis, a given parameter reaches a stable plateau at the time when the mean value is no longer significantly different $(P>0.05)$ from the subsequent mean values.

\section{Results}

Isovolemic exchange of $9.7 \pm 2.3 \mathrm{ml} / \mathrm{kg}$ of blood by dextran 60 reduced the Hct from $34 \%$ to $30 \%$. After hemodilution, Hct and $\mathrm{Hb}$ did not change significantly up to $\mathrm{T}_{150}$ (Table 1$)$.

\section{Hemodynamics}

The injection of OA and GB $(0.46 \pm 0.13 \mathrm{~g} / \mathrm{kg})$ resulted in a marked increase of PAP $(11 / 37 \mathrm{~mm} \mathrm{Hg})$ and RVP $(8 / 20 \mathrm{mmHg})$ at $\mathrm{T}_{10}$ (Fig. 1a, b). Concomitantly, PVR rose from 115 to $622 \mathrm{dyn} \cdot \mathrm{s} / \mathrm{cm}^{5}$ (Fig. 1c) and RVSW increased from 57 to $149 \mathrm{Nm} \cdot 10^{-3}$ (Table 1 ). Within the next $40 \mathrm{~min}$ there was a considerable fall in

Fig. 1A-C. Sequence of changes in A mean pulmonary artery pressure (PAP), B mean right ventricular pressure (RVP) and C calculated pulmonary vascular resistance (PVR) after injection of OA/GB. Data (means $\pm \mathrm{SD} ; n=8$ ) are levels before (control) and at $10-150 \mathrm{~min}$ after embolization $\left.T_{10}-T_{150}\right)$. The length of the rastered area indicates the time needed for each parameter to stabilize, while the rest of time up to $T_{150}$ and not marked by a raster indicates the plateau without any significant trend (n.s.) of the data to higher or lower values (for statistics see Methods). To estimate the significance of acute and long-term effects after $\mathrm{OA} / \mathrm{GB}$, data recorded at $\mathrm{T}_{10}, \mathrm{~T}_{30}$ and $\mathrm{T}_{150}$ have been compared with control data by means of Student's $t$-test $\left({ }^{*} P<0.05 ;{ }^{* *} P<0.01 ;{ }^{* * *} P<0.001\right)$

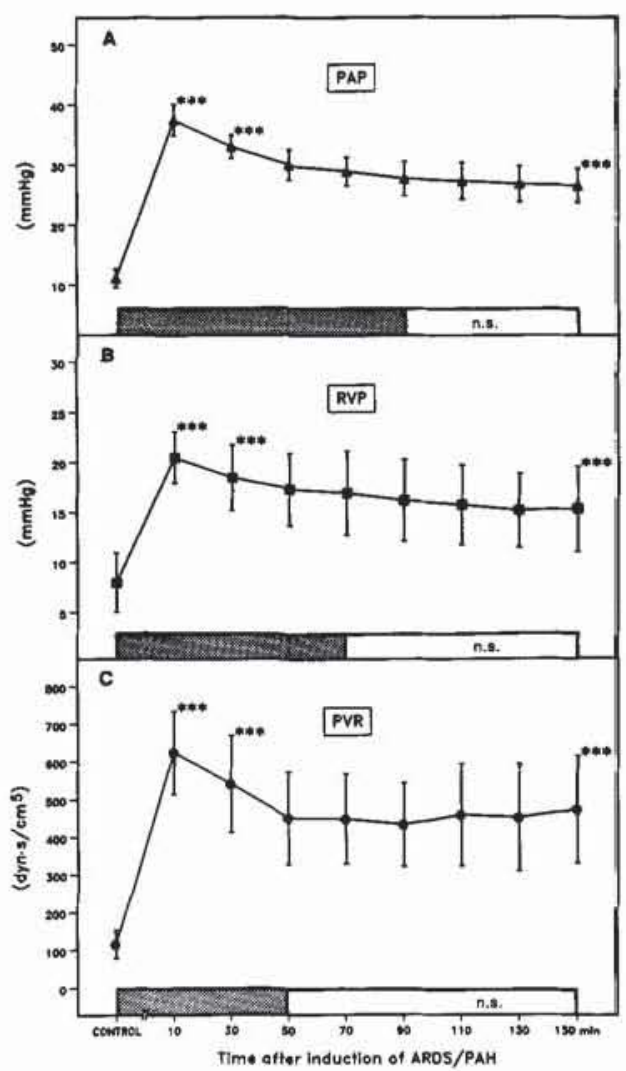




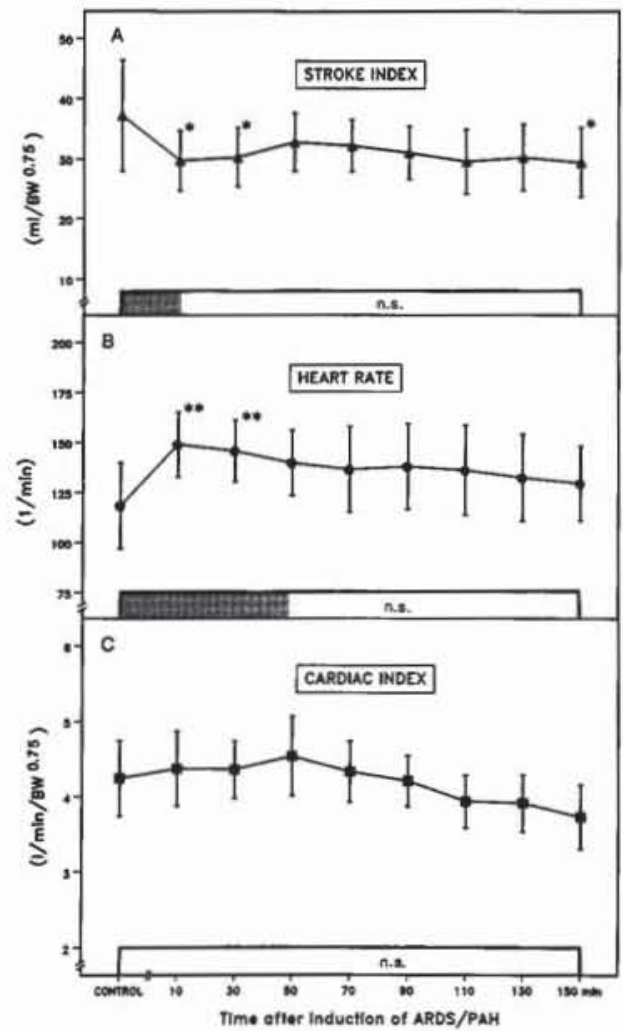

Fig. 2A-C. Sequence of changes in $\mathbf{A}$ stroke index, $\mathbf{B}$ heart rate, and $\mathbf{C}$ cardiac index after injection of OA/GB. For further explanation see legend to Fig. 1

PAP, RVP, and PVR, as well as in RVSW. Yet, PVR had completely stabilized at a high plateau at $T_{50}$ and showed no further change up to $T_{150}$. Although Helmert analysis revealed a significant trend to lower values for RVP/RVSW and PAP up to $T_{70}$ and $T_{90}$, respectively, the absolute changes remained small.

RVEDP and CVP were slightly, but persistently, increased after injection of $\mathrm{OA} / \mathrm{GB}$ (Table 1). A significant reduction of $\mathrm{SI}$ at $\mathrm{T}_{10}$ persisted throughout the experiment (Fig. 2A) and was accompanied by a rise in HR (Fig. 2B) resulting in an unchanged $\mathrm{CI}$ (Fig. 2C). The injection of $\mathrm{OA} / \mathrm{GB}$ provoked a sudden fall $\left(\mathrm{T}_{10}\right)$ of LVP $(47 / 43 \mathrm{mmHg}$; Fig. 3A), MAP $(106 / 89 \mathrm{~mm} \mathrm{Hg})$, LVEDP (5.2/ $3.8 \mathrm{~mm} \mathrm{Hg}$ ), and LVSW (540/358 Nm $\cdot 10^{-3}$; Table 1). SVR decreased (Fig. 3B) and was the only parameter that did not stabilize within $150 \mathrm{~min}$, while LVP, LVEDP and MAP returned to control within $50 \mathrm{~min}$ and LVSW remained at low values from $T_{50}-T_{150}$.

\section{Lung Function}

Lung mechanics and gas exchange were significantly altered by injection of $\mathrm{OA} /$ GB (Fig. 4): a $17 \%$ reduction in $\mathrm{C}_{\text {eff }}\left(42 / 35 \mathrm{ml} / \mathrm{cm} \mathrm{H}_{2} \mathrm{O}\right)$ at $\mathrm{T}_{30}$ was paralleled by a $20 \%$ increase of $R_{\exp }\left(10.4 / 12.5 \mathrm{~cm} \mathrm{H}_{2} \mathrm{O} \cdot \mathrm{s} / \mathrm{l}\right)$. No change occurred within the next $2 \mathrm{~h} . \mathrm{P}_{\mathrm{a}} \mathrm{O}_{2}$ decreased by $31 \%(547 / 379 \mathrm{~mm} \mathrm{Hg})$ at $\mathrm{T}_{30}$, while $\dot{\mathrm{Q}}_{\jmath} / \dot{\mathrm{Q}}_{\mathbf{1}}$ and 


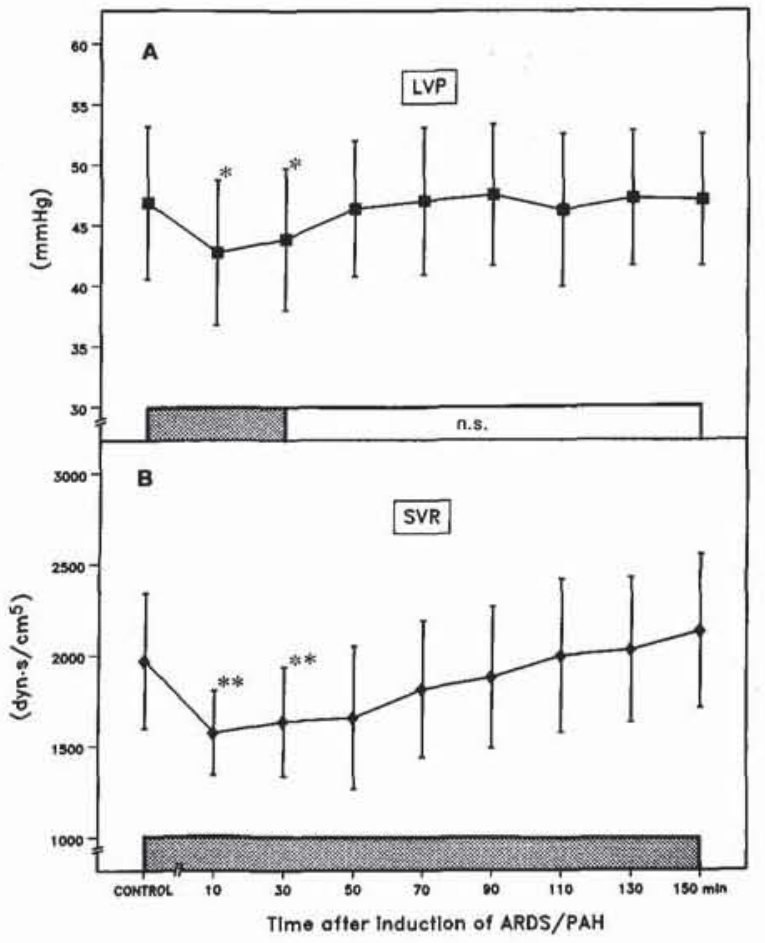

Fig. 3A, B. Sequence of changes in $\mathbf{A}$ mean left ventricular pressure and $\mathbf{B}$ systemic vascular resistance after injection of $\mathrm{OA} / \mathrm{GB}$. For further explanation see legend to Fig. 1

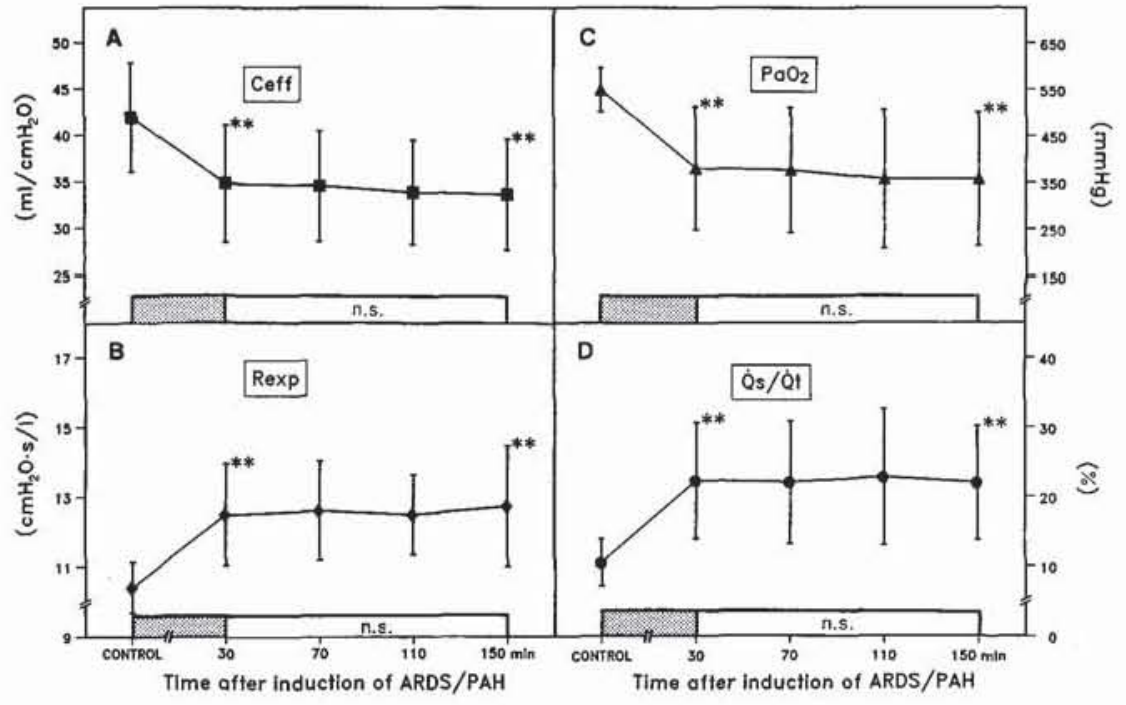

Fig. 4A-D. Sequence of changes in $\mathrm{A}$ effective pulmonary compliance, $\mathrm{B}$ expiratory pulmonary resistance, $\mathbf{C} \mathrm{P}_{\mathrm{a}} \mathrm{O}_{2}$, and $\mathbf{D}$ intrapulmonary shunt after injection of $\mathrm{OA} / \mathrm{GB}$. Data (means $\pm \mathrm{SD} ; n=8$ ) are levels before (control) and at $30,70,110$ and $150 \mathrm{~min}$ after embolization $\left(T_{30}-T_{150}\right)$. Data recorded at $T_{30}$ and $T_{150}$ have been compared with control data by means of Student's $t$-test $\left({ }^{* *} P<0.01\right)$. For further explanations see legend to Fig. 1 


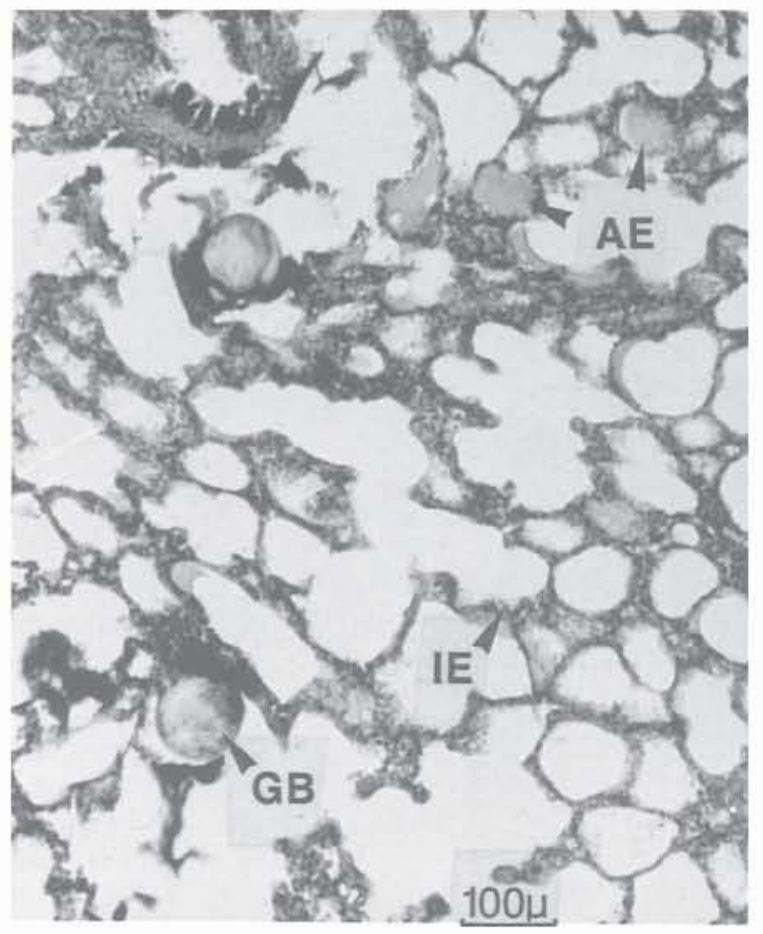

Fig. 5. Histological section of the lung after the administration of oleic acid and glass beads: Note the interstitial and the intraalveolar edema formation. $G B$, glass bead; $I E$, interstitial edema; $A E$, intraalveolar edema (original magnification $\times 60)$

$\mathrm{AaDO}_{2}$ more than doubled (10.6/22.3\% and $126 / 301 \mathrm{~mm} \mathrm{Hg}$, respectively). An increase in $\mathrm{V}_{\mathrm{D}} / \mathrm{V}_{\mathrm{T}}(51 / 61 \%)$ was accompanied by hypercapnia and mild respiratory acidosis (Table 1). Similarly to lung mechanics, gas exchange had stabilized at $T_{30}$ and persisted unchanged throughout the study.

COP was significantly reduced at $\mathrm{T}_{30}\left(23.6 / 19.9 \mathrm{~cm} \mathrm{H}_{2} \mathrm{O}\right.$; Table 1$)$ without any further change up to $T_{150}$.

\section{Histology}

Histological examination of the lung revealed a mild, interstitial and intraalveolar edema (Fig. 5). Some of the injected GB were found within alveoles, possibly indicating destruction of the blood-alveolar barrier. GB were not found in coronary vessels or in the myocardial tissue.

\section{Discussion}

The acute onset of PAH has the potential to impair cardiac function [35] and to worsen the prognosis of patients with ARDS [33]. To investigate the underlying pathophysiological mechanisms, an experimental model of ARDS and pulmonary artery hypertension has been developed in the present study. Dogs have been chosen as the experimental animal, because this species is commonly used when cardiac function is investigated in the setting of respiratory failure or PAH. 


\section{Cardiovascular Effects of $O A / G B$}

The injection of OA/GB resulted in a marked increase of pulmonary vascular resistance and RV afterload. This reaction has been already described by Malik et al., who measured PAP and PVR for a total of $60 \mathrm{~min}$ after injection of $100 \mu \mathrm{m}$ GB in dogs [28]. Presumably, the rise in PVR is caused by a combination of the effects of mechanical obstruction in small blood vessels (by GB and/ or platelets), of active vasoconstriction subsequent to stimulation of pulmonary stretch receptors [23], and the release of vasoactive substances [26].

Between $T_{10}$ and $T_{50}$ we observed a considerable drop in PVR, PAP, and RVP, followed by a stable plateau at $50-70 \mathrm{~min}$ post embolization. This is in contrast to the finding of Malik, who did not measure any change in PAP and PVR once peak levels had been reached [28]. The reasons for this discrepancy are not clear because the experimental settings have basically been the same (dogs, $100 \mu \mathrm{m} \mathrm{GB}$ ). The simultaneous use of OA in our experiments - because of its ability to create pulmonary edema - could explain a further increase but not a decrease in PVR and PAP [19]. While the latter can be attributed to microemboli being pushed downstream by the blood flow (resulting in less obstruction of larger vessels) or to the elimination of vasoactive substances by metabolism and to active pulmonary vasodilatation [24], a stabilization of PVR at the very peak level is more difficult to understand. Possibly, in the study of Malik et al., PVR was maintained by a higher degree of hypoxic pulmonary vasoconstriction consequent on a low $\mathrm{P}_{3} \mathrm{O}_{2}$ after $\mathrm{GB}$ injection $(60 \mathrm{~mm} \mathrm{Hg})$ as against the high $\mathrm{P}_{\mathrm{a}} \mathrm{O}_{2}$ of $379 \mathrm{~mm} \mathrm{Hg}$ obtained in the present experiments.

The fall of LVP, LVSW, MAP, and SVR in the initial phase after OA/GB is explained by a reduced LVEDP at that time. Except for LVSW, the parameters had returned to control levels within $50 \mathrm{~min}$. No depression of cardiac output was observed. Together with normal LV hemodynamics this indicates that the injection of OA and of GB did not impair LV function in our model. This finding is in agreement with those of McIntyre and Sasahara, who reported that $\mathrm{PAP}$ as high as $38 \mathrm{~mm} \mathrm{Hg}$ may occur without reduction of $\mathrm{CO}$ after acute pulmonary embolism [29]. Furthermore, any possibility that a progressive depression of myocardial contractility, as described recently after bolus injection of pentobarbital [17], might have influenced our results can be excluded. The reduction of $\mathrm{CO}$ found in studies using higher doses of OA [19] may be due to the volume deficit originating from the fluid losses into the lung in presence of major endothelial damage [37]. In our model the application of only $0.01 \mathrm{ml} / \mathrm{kg}$ OA resulted in moderate pulmonary edema, but obviously did not cause a volume deficit apt to lower arterial pressure. Thus, the present model allows to study cardiac function without disturbance by time-dependent changes of RV and LV performance inherent in the experimental model.

\section{Effects of $O A / G B$ on Lung Function}

The mechanisms by which $\mathrm{OA}$ and GB induce respiratory failure are not yet clearly understood $[19,31]$. However, striking pathophysiological and histological similarities between ARDS and lung injury induced by OA or GB have 
been found. Both substances provoke pulmonary edema. While OA is thought to directly injure the pulmonary endothelium [31], GB results in the release of mediators, which in turn cause lung edema [26]. Edema formation is potentiated in this situation, because the pulmonary hydrostatic pressure is increased as a result of GB injection [26].

In the present study a significant increase of $\dot{Q}_{S} / \dot{Q}_{t}, A_{a D O}, V_{D} / V_{T}$ and $R_{\exp }$ as well as a decrease of $\mathrm{P}_{\mathrm{a}} \mathrm{O}_{2}$ and $\mathrm{C}_{\text {eff }}$ was found. Thus, the typical clinical symptoms of ARDS [2] were present in our model. The relatively high $V_{D} / V_{T}$ of $51 \%$ at control seems to be valid: standard techniques have been used for its determination and similar values have been demonstrated by others in anesthetized and ventilated dogs as well as in baboons $[11,18]$.

It is difficult to assess to what extent either OA or GB contributed to the pathological changes in lung function. Using $100 \mu \mathrm{m}$ GB alone in nonheparinized dogs at a $\mathrm{FiO}_{2}$ of 1.0, no disturbances of gas exchange have been found in our own pilot experiments. This is in accordance with Beckett et al., who failed to detect a substantial impairment of oxygenation after GB [5]. On the other hand, GB and additional application of more than $0.025-0.05 \mathrm{ml} / \mathrm{kg}$ $\mathrm{OA}$ resulted in severe and progressive hypoxemia with $\mathrm{P}_{\mathrm{a}} \mathrm{O}_{2}$ levels too low ( $<50 \mathrm{~mm} \mathrm{Hg}$; authors' unpublished data) to be acceptable for a model designed to investigate cardiac function. As a consequence of the low dose of $\mathrm{OA}$ used in the present study, $\mathrm{O}_{2}$ saturation did not fall below $90 \%$. Moreover, as demonstrated by Helmert analysis, changes in lung function had stabilized within $30 \mathrm{~min}$ after the last injection of GB and persisted for $2 \mathrm{~h}$. Thus, cardiac function can be studied in this model without interference with time-dependent alterations in lung function.

\section{Histology}

Histology of the lung revealed pathological alterations similar to ARDS. The presence of interstitial and intraalveolar edema together with a decrease in COP indicates microvascular lung injury with endothelial defects and partial destruction of the blood-alveolar barrier.

A complete first-pass trapping in the lungs has already been described for particles much smaller than $100 \mu \mathrm{m}$. Since no GB have been encountered in sections of the myocardium, we can exclude that GB passing through the lungs caused microinfarctions.

We conclude that the present model satisfies the criteria for both ARDS and PAH in the dog and allows for the study of cardiac function in the presence of respiratory insufficiency and a high PVR. It may therefore contribute to a better understanding of mechanisms limiting cardiac performance in patients with ARDS and PAH.

Acknowledgement. The authors thank PD Dr. G. Mall for the histological analysis. The expert technical assistance of Mrs. R. Schwarz, J. Schulte, and K. Sonnenberg is gratefully acknowledged. 


\section{References}

1. Arfors KE, Busch C, Jacobson S, Lindquist O, Malmberg P, Rammer L, Saldeen T (1972) Pulmonary insufficiency following intravenous infusion of thrombin and AMCA (tranexamic acid) in the dog. Acta Chir Scand 138:445-452

2. Artigas A (1988) Adult respiratory distress syndrome: Changing concepts of clinical evolution and recovery. In: Vincent JL (ed) Update in intensive care and emergency medicine, vol 5. Springer, Berlin Heidelberg New York, p 97

3. Ashbaugh DG, Uzawa T (1968) Respiratory and hemodynamic changes after injection of free fatty acids. J Surg Res 8:417-423

4. Barie PS, Minnear FL, Malik AB (1981) Increased lung vascular permeability after bone marrow injection in sheep. Am Rev Respir Dis 123:648-653

5. Beckett RC, Gray BA (1982) Effect of atelectasis and embolization on extravascular thermal volume of the lungs. J Appl Physiol 53:1614-1619

6. Bishop MJ, Cheney FW (1983) The effects of hemodilution during pulmonary edema in dogs. Ann Surg 198:96-101

7. Brigham KL, Myrick B (1986) Endotoxin and lung injury. Am Rev Respir Dis 133:913927

8. Brigham KL, Woolverton WC, Blake LH, Staub NC (1974) Increased sheep lung vascular permeability caused by pseudomonas bacteremia. J Clin Invest 54:792-804

9. Busch C, Rammer L (1973) Quantitation of fibrin deposition and elimination in organs of rats injected with labelled fibrinogen by isolation of the labelled fibrin from water soluble tracer. Thromb Diath Haemorrh 29:108-114

10. Calvin JE, Baer RW, Glantz SA (1985) Pulmonary artery constriction produces a greater right ventricular dynamic afterload than lung microvascular injury in the open chest dog. Circ Res 56: 40-56

11. Coffey RL, Albert R, Robertson HT (1983) Mechanisms of physiological dead space response to PEEP after acute oleic acid lung injury. J Appl Physiol 55:1550-1557

12. Derks CM, Jacobovitz-Derks D (1977) Embolic pneumopathy induced by oleic acid. Am J Pathol 87: 143-158

13. Dexter L, Smith GT (1964) Quantitative studies of pulmonary embolism. Am J Med Sci $35: 641-648$

14. Enghoff H (1938) Volumen inefficax. Bemerkungen zur Frage des schädlichen Raumes. Upsala Laekarefoeren Foerh 44:191-218

15. Esbenshade AM, Newman JH, Lams PM, Jolles H, Brigham KL (1982) Respiratory failure after endotoxin infusion in sheep: lung mechanics and lung fluid balance. J Appl Physiol 53:967-976

16. Gottlieb SS, Wood LDH, Hansen DE, Long GR (1987) The effect of nitroprusside on pulmonary edema, oxygen exchange, and blood flow in hydrochloric acid aspiration. Anesthesiology 67:203-210

17. Hansen DE, Borow KM, Neumann A, Lang RM, Fujii AM, Schumacker PT, Wood LDH (1986) Effects of acute lung injury and anesthesia on left ventricular mechanics. Am J Physiol 251:1195-1204

18. Hammon JW, Wolfe WG, Moran JF, Jones RH, Sabiston DC (1976) The effect of positive end-expiratory pressure on regional ventilation and perfusion in the normal and injured primate lung. J Thorac Cardiovasc Surg 72:680-689

19. Hofman WF, Ehrhart IC, Granger WM, Miller DA (1985) Sequential cardiopulmonary changes after oleic-acid injury in dogs. Crit Care Med 13:22-27

20. Holt JP, Rhode EA, Kines H (1968) Ventricular volumes and body weight in mammals. Am J Physiol 215:704-715

21. Hurley JV (1977) Current views on the mechanisms of pulmonary oedema. J Pathol 125 59-79

22. Johnson A, Malik AB (1981) Effects of different-size microemboli on lung fluid and protein exchange. Am J Physiol 51:461-464

23. Juratsch CE, Lengo JA, Laks MM (1977) Role of the autonomic nervous system and pulmonary artery receptors in production of experimental pulmonary hypertension. Chest 71 [Suppl]:265-268 
24. Kealey GP, Brody MJ (1977) Studies on the mechanism of pulmonary vascular responses to miliary pulmonary embolism. Circ Res $41: 807-814$

25. Machida K, Rapaport E (1971) Left ventricular function in experimental pulmonary embolism. Jpn Heart J 12:221-232

26. Malik AB (1983) Pulmonary microembolism. Physiol Rev 63:1114-1207

27. Malik AB, Van der Zee H (1977) Thrombin-induced pulmonary insufficiency. Thromb Res $11: 497-506$

28. Malik AB, Van der Zee H (1977) Timecourse of pulmonary vascular response to microembolization. J Appl Physiol 43:51-58

29. McIntyre KM, Sasahara AA (1971) The hemodynamic response to pulmonary embolism in patients without prior cardiopulmonary disease. Am J Cardiol 28:288-294

30. Mink SN, Gomez A, Whitley L, Coalson JJ (1986) Hemodynamics in dogs with pulmonary hypertension due to emphysema. Lung $164: 41-54$

31. Motohiro A, Furukawa T, Yasumoto K, Inokuchi K (1986) Mechanisms involved in acute lung edema induced in dogs by oleic acid. Eur Surg Res 18:50-57

32. Ohkuda K, Nakahara K, Weidner WJ, Binder A, Staub NC (1978) Lung fluid exchange after uneven pulmonary artery obstruction in sheep. Circ Res 43:152-161

33. Oliphant LD, Sibbald WJ (1987) Right ventricular performance in the adult respiratory distress syndrome. In: Vincent JL, Suter PM (eds) Update in intensive care and emergency medicine, vol 4. Springer, Berlin Heidelberg New York, p 25

34. Plopper CG, Dunworth DL, Tyler WS (1973) Pulmonary lesions in rats exposed to ozone. Am J Pathol 71:375-394

35. Qvist J, Mygind T, Crottogini A, Jordening H, Mogensen T, Dorph S, Laver MB (1988) Cardiovascular adjustments to pulmonary vascular injury in dogs. Anesthesiology 68 : 341-349

36. Raper R, Sibbald WJ (1987) Right ventricular function in the surgical patient. World J Surg 11:154-160

37. Schuster DP, Trulock EP (1984) Correlation of changes in oxygenation, lung water and hemodynamics after oleic acid-induced acute lung injury in dogs. Crit Care Med 12:10441048

38. Sielaff TD, Sugerman HJ, Tatum JL, Blocher CR (1987) Successful treatment of adult respiratory distress syndrome by histamin and prostaglandin blockade in a porcine pseudomonas model. Surgery 102:350-357

39. Woolverton WC, Hyman AL (1972) The pulmonary hemodynamic effects of lung thromboemboli in dogs. Surgery 73:572-578

40. Zelter M, Douguet D (1986) Experimental pulmonary oedemas. Bull Eur Physiopathol Respir 22:281-314 